\title{
CDISC SEND Microscopic Findings Test Code Terminology
}

National Cancer Institute

\section{Source}

National Cancer Institute. CDISC SEND Microscopic Findings Test Code Terminology.

NCI Thesaurus. Code C89974.

The terminology that includes concepts relevant to the Clinical Data Interchange Standards Consortium (CDISC) Standard for the Exchange of Non-clinical Data (SEND) microscopic findings test short names. 